\title{
Short-Term Outcomes of Colorectal Endoscopic Submucosal Dissection Performed by Trainees
}

\author{
Taku Sakamoto Chiko Sato Makomo Makazu Masau Sekiguchi Genki Mori \\ Masayoshi Yamada Yuzuru Kinjo Eriko Turuki Seiichiro Abe Yosuke Otake \\ Takeshi Nakajima Takahisa Matsuda Yutaka Saito
}

Endoscopy Division, National Cancer Center Hospital, Tokyo, Japan

\section{Key Words}

Endoscopic submucosal dissection · Colon · Trainee .

Learning curve

\begin{abstract}
Background: Colorectal endoscopic submucosal dissection (ESD) is a relatively new therapy that has been accepted as the most effective treatment procedure for superficial colorectal neoplasms. Given the increasing acceptance and use of this procedure worldwide, the outcomes of colorectal ESD performed by trainees should be understood from a practical perspective and for developing strategies to introduce ESD to trainees. This study aimed to evaluate the clinical outcomes of ESD when conducted by less-experienced endoscopists. Summary: We retrospectively reviewed the clinical outcomes of 164 patients with 164 colorectal neoplasms who underwent ESD carried out by 20 trainees performing their first colorectal ESDs between April 2005 and March 2012. For each operator, clinical data were collected between the first and 30th cases. For evaluating the technical aspects of the ESD procedure, the endoscopic characteristics of the lesions, procedure time, en bloc resection rate, R0 resection rate, invasion depth and complications were evaluated. The median procedure time was $95 \mathrm{~min}$; about $75 \%$ of the lesions were resected within $120 \mathrm{~min}$. Apparent
\end{abstract}

perforation or electric damage in the muscularis propria was seen in $4 \%$ of lesions. In terms of factors with the potential to effect procedure time, lesion size and pathological invasion depth were significantly different between shorter and longer treatment times for granular-type laterally spreading tumors (LST). Key Messages: A granular-type LST of $<40 \mathrm{~mm}$ is a good lesion for introducing colorectal ESD to trainees. Trainees should have a strong ability to make a depth diagnosis before starting ESD.

(c) 2014 S. Karger AG, Basel

\section{Introduction}

The use of endoscopic submucosal dissection (ESD) for large colorectal neoplasms is gradually increasing because the procedure has a low incidence of local recurrence and shows histologically accurate evaluation of the neoplasm as a result of en bloc resection, regardless of tumor size. However, the procedure also has several disadvantages, including technical difficulty and the risk of perforation. Good clinical short-term outcomes have been reported, especially from Japan, even though these procedures are considered to have been performed largely by endoscopists with limited skills in major institutions [1-9]. Given the limited experience, the clinical short- 
term outcomes of general endoscopists new to ESD should be evaluated to enable the further widespread use of this procedure, in particular through improvements in the training process. Accordingly, various surgical parameters and outcomes need to be examined in regards to lesion characteristics during the training process in order to recommend lesions with the appropriate characteristics for training less-experienced endoscopists.

We have previously reported the clinical outcomes of colorectal ESD performed by trainees and clarified the learning curve for this procedure. We found that trainees required experience with $>30$ cases to perform colorectal ESD without guidance from an experienced specialist [10]. However, one of the study limitations was that the results were calculated based on the experience of only 2 endoscopists in training. An additional study was needed to validate the data for the treatment outcomes using a much greater number of less-experienced endoscopists.

The aims of this study were to re-evaluate the clinical outcomes of ESD when conducted by less-experienced endoscopists and to suggest recommendations for the introduction of ESD to trainees.

\section{Methods}

We retrospectively reviewed the clinical outcomes of 164 patients with 164 colorectal neoplasms who underwent ESD by 20 trainees who were performing their first colorectal ESDs under the guidance of experienced specialists at the National Cancer Center, Tokyo, Japan, between April 2005 and March 2012. For each operator, clinical data were collected between the first and 30th cases. We conducted this study in accordance with the guidelines of our institutional review board, which approved this retrospective study without the need for informed consent. All of the patients provided written informed consent for the colonoscopy and ESD.

\section{Indications for Colorectal ESD}

A requirement for endoscopic treatment was that the lesions had to show a noninvasive pattern upon magnifying chromoendoscopy. An invasive pattern was considered to be characterized by irregular and distorted pits in a demarcated area, suggesting deep submucosal invasion $(\geq 1,000 \mu \mathrm{m})$ and thus a high risk of lymph node metastasis. A noninvasive pattern was one not showing these characteristics, suggesting intramucosal neoplasia or superficial submucosal invasion $(<1,000 \mu \mathrm{m})[11,12]$. We defined the indications for ESD as: (1) a laterally spreading tumor (LST) non-granular (LST-NG)-type lesion of $>20 \mathrm{~mm}$ in size, (2) an LST granular (LST-G) nodular mixed-type lesion of $>30 \mathrm{~mm}$ in size these lesions have a high submucosal invasion rate and require histologically accurate removal by en bloc resection - and (3) large villous tumors, recurrent lesions and residual intramucosal lesions showing the nonlifting sign after endoscopic mucosal resection were also considered candidates for ESD.

\section{ESD Procedure}

The trainees performed the procedure using a ball-tip-type bipolar needle knife (B-B knife; XEMEX Co., Tokyo, Japan), in which the electrical current localizes to the needle tip with carbon dioxide insufflations $[1,13]$. Bipolar coagulation forceps were also routinely applied to stop active bleeding and decrease the risk of perforation. The lesion margins were clearly delineated before circumferential incision using a $0.4 \%$ indigo carmine dye spray. After injecting $10 \%$ glycerol and 5\% fructose in a normal saline solution (Glyceol; Chugai Pharmaceutical Co., Tokyo, Japan) and sodium hyaluronate into the submucosal layer under the tumor, the trainees incised the mucosa with the B-B knife about 2-3 mm outside the lesion edge on the elevation caused by the submucosal injection. An additional submucosal injection of the same solution was then applied before ESD to prevent perforation. An insulated-tip knife (IT knife; Olympus Optical Co., Tokyo, Japan) or B-B knife was used to dissect the submucosal layer. The electric current used for the circumferential incision and submucosal dissection was set to endocut mode (effect 3; output $50 \mathrm{~W}$; ERBE ICC-200; ERBE Elektromedizin $\mathrm{GmbH}$, Tübingen, Germany).

\section{Histopathological Assessment}

All resected specimens were fixed in $10 \%$ buffered formalin and were cut into 2 -mm-thick slices. These were embedded in paraffin, cut into $3-\mu \mathrm{m}$ sections, stained with hematoxylin and eosin, and microscopically examined for histopathologic type by pathologists specializing in gastrointestinal pathology.

Resections were evaluated according to the presence of tumor cells at the margins of the resected specimen, independent of its histopathological features, as follows: R0 resection - all margins were negative for cancer cells; R1 resection - cancer except for adenoma cells extending to the lateral or basal margins, and Rx resection - the margins could not be evaluated. The histopathological diagnoses were based on the Japanese classification criteria for cancer of the colon and rectum and the Vienna classification system $[11,14]$.

\section{Statistical Analysis}

For evaluating the technical aspect of the ESD procedure, the endoscopic characteristics of the lesions, procedure time, en bloc resection rate, $\mathrm{R} 0$ resection rate, invasion depth and complications were evaluated. For comparisons between groups, the variables were analyzed with the Kruskal-Wallis test for data showing nonnormality and the $\chi^{2}$ test for nominal scale data. In terms of the group comparison, we compared factors that can affect the procedure time, and divided the lesions into 2 groups on the basis of whether or not the procedure required more than $2 \mathrm{~h}$. All statistical analyses were performed using STATA 10.0 (StataCorp, College Station, Tex., USA). All tests were two-sided, and $\mathrm{p}<0.05$ was considered statistically significant by Fisher's exact probability test.

To categorize the lesions for the statistical analysis, the procedure time was considered with respect to acceptability in practice. A cut-off time of $2 \mathrm{~h}$ was decided based on the results of the prospective multicenter study of colorectal ESD reported by Saito et al. [2], in which the mean procedure time was approximately $2 \mathrm{~h}$.
38 
Table 1. Clinical characteristics of resected lesions

\begin{tabular}{ll}
\hline Location, $\mathrm{n}$ & \\
Colon & $84(51)$ \\
Rectum & $63(38)$ \\
Cecum & $17(10)$ \\
Median size, mm & $30(25-40)$ \\
Macroscopic type, $\mathrm{n}$ & \\
$\quad$ LST-G $(0-$ Is + IIa) & $87(53)$ \\
$\quad$ LST-NG (0-IIa, IIa + IIc) & $37(23)$ \\
$\quad$ Flat elevated & $15(9)$ \\
$\quad$ Pseudo-depressed & $15(9)$ \\
$\quad$ Protruded (0-Is) & $10(6)$ \\
$\quad$ Recurrence & $140(85)$ \\
Histological depth, $\mathrm{n}$ & $15(9)$ \\
$\quad$ Intramucosal & $9(6)$ \\
Submucosal & \\
$\quad<1,000 \mu \mathrm{m}$ & \\
$\quad \geq 1,000 \mu \mathrm{m}$ &
\end{tabular}

\section{Results}

The number of treatments performed by each endoscopist was as follows: 16 performed less than 15 colorectal ESDs, while 4 performed about 30 cases. The clinical characteristics of the resected lesions are shown in table 1. The median lesion size was $30 \mathrm{~mm}$ (interquartile range 24-40); the lesion locations were the colon $(n=84)$, rectum $(n=63)$ and cecum $(n=17)$. In terms of the macroscopic type, 87 lesions were the LST-G type, 52 the LST-NG type, 15 the protruded type and 10 were local recurrence after initial endoscopic treatment. Table 2 summarizes the short-term outcomes of ESDs. The median procedure time was $95 \mathrm{~min}$ and about $75 \%$ of all lesions were resected within $120 \mathrm{~min}$. Apparent perforation or electric damage in the muscularis propria layer was seen in 7 lesions (4\%). They were able to be monitored using only conservative treatment with antibiotics. Minor bleeding occurred in almost all resections, but blood transfusion was not required because hemostasis was achieved during the procedure. Delayed bleeding after ESD occurred in 5 lesions (3\%). All these cases were successfully treated with endoscopic hemostasis without blood transfusion. En bloc resection was achieved in 95\% of all procedures. In terms of pathological evaluation, $92 \%$ were judged as an $\mathrm{R} 0$ resection. When we analyzed the short-term outcomes of median procedure time (interquartile range), en bloc resection rate and perforation
Table 2. Clinical outcomes of ESDs

\begin{tabular}{lc}
\hline Median procedure time, min & $95(60-120)$ \\
Complications & \\
$\quad$ Perforation, $\mathrm{n}$ & $7(4)$ \\
Delayed bleeding, $\mathrm{n}$ & $5(3)$ \\
En bloc resection, $\mathrm{n}$ & $155(95)$ \\
Resectability, $\mathrm{n}$ & $151(92)$ \\
R0 & $13(8)$ \\
R1 & \\
\hline \multicolumn{2}{l}{ Values in parentheses are either percentages or interquartile } \\
range.
\end{tabular}

rate according to the macroscopic type, the results were as follows: $120(20-480) \mathrm{min}, 93$ and $6 \%$ in the LST-G type; $85.5(30-210) \mathrm{min}, 100$ and $0 \%$ in the LST-NG type; 70 (30-190) $\mathrm{min}, 100$ and $7 \%$ in the protruded type, and $105(18-540) \mathrm{min}, 90$ and $10 \%$ in the recurrent lesion.

Table 3 shows the results of the analysis for factors with the potential to affect the procedure time. For the LST-G type, the lesion size and pathological depth of invasion were significantly different between procedures of $<2 \mathrm{~h}$ in duration and those of $\geq 2 \mathrm{~h}$. However, for the LSTNG type, no significant differences were observed in the various examined parameters between the shorter and longer procedure times.

\section{Discussion}

We described here the short-term outcomes following ESD performed by less-experienced endoscopists. Most of the short-term outcomes reported previously were considered to be based on the clinical outcomes of ESDs performed by experienced endoscopists in highly advanced institutions. Therefore, considering standardization, we believe that our study has considerable meaning for less-experienced endoscopists. In our previous study, we analyzed the proportion of complete procedures, that is, those completely performed by the trainee without any technical assistance. LST-NG and recurrent lesions were found to be significantly more difficult than LST-G-type lesions. We concluded that the LST-G lesion was a suitable one for training less-experienced endoscopists to perform colorectal ESD. In terms of the results of the present study, we analyzed the clinical short-term outcomes for both LST-G and LST-NG lesions. We found that the outcomes for LST-NG were extremely good; en 
Table 3. Clinical features of LSTs classified according to procedure time and morphology

\begin{tabular}{|c|c|c|c|c|c|c|}
\hline & \multicolumn{3}{|l|}{ LST-G } & \multicolumn{3}{|l|}{ LST-NG } \\
\hline & $<2 \mathrm{~h}(\mathrm{n}=43)$ & $\geq 2 \mathrm{~h}(\mathrm{n}=44)$ & $\mathrm{p}$ value & $<2 \mathrm{~h}(\mathrm{n}=40)$ & $\geq 2 \mathrm{~h}(\mathrm{n}=12)$ & $\mathrm{p}$ value \\
\hline Median size, $\mathrm{mm}$ & $32(29-40)$ & $40(35-55)$ & $<0.001$ & $25(20-30)$ & $30(24-35)$ & 0.085 \\
\hline \multicolumn{7}{|l|}{ Location, $\mathrm{n}$} \\
\hline Cecum & $7(16)$ & $6(14)$ & & $2(5)$ & $0(0)$ & 0.800 \\
\hline Colon & $13(30)$ & $23(52)$ & 0.104 & $31(78)$ & $11(92)$ & \\
\hline Rectum & $23(53)$ & $15(34)$ & & 7 (18) & $1(8)$ & \\
\hline \multicolumn{7}{|l|}{ Macroscopic subtype, $\mathrm{n}$} \\
\hline Flat elevated & & & & $29(73)$ & $8(67)$ & 0.726 \\
\hline Pseudo-depressed & & & & $11(28)$ & $4(33)$ & \\
\hline \multicolumn{7}{|l|}{ Depth, n } \\
\hline Intramucosal & $41(95)$ & $35(80)$ & 0.049 & $30(75)$ & $11(92)$ & 0.421 \\
\hline Submucosal & $2(5)$ & $9(20)$ & & $10(25)$ & $1(8)$ & \\
\hline En bloc resection, $\mathrm{n}$ & $42(98)$ & $39(87)$ & 0.202 & $40(100)$ & $12(100)$ & - \\
\hline
\end{tabular}

Values in parentheses are either percentages or interquartile range.

bloc resection was achieved for all lesions without any adverse events. Moreover, no significant differences were found in the clinical outcomes according to procedure time. However, these results would have been influenced by an experienced endoscopist's assistance.

Meanwhile, for the LST-G-type lesions, significant differences were observed in the lesion size and invasion depth according to the procedure time. Hence, lesions of a greater size and invasion depth required a longer procedure when less-experienced endoscopists tried to resect them by ESD. In general, LST-G lesions seem to resect more easily than LST-NG lesions because of the good lifting after submucosal injection. The combination of the good lifting and the low incidence of perforation during submucosal dissection is the primary reason we consider LST-G lesions to be suitable for introducing ESD to trainees.

Various factors can influence the technical difficulty of ESD, such as lesion location and size. With respect to lesion location, the probability that the lesion has bridged over the haustra is increased with lesion size. If the lesion is located on the haustra or flexion site, the ESD procedure could be more difficult than in other situations. Hence, the statistically significant differences in lesion size for the procedure time with the LST-G type might reflect this potential difference between smaller and larger lesions.

The present study also found that the depth of invasion of the lesions influenced the procedure time. Tumor invasion into the submucosal layer is generally associated with submucosal fibrosis, which can decrease the safety of the ESD procedure [15-17]. Additionally, the technical difficulty of the procedure is strongly related to the risk of perforation. Perforation during ESD and closure using an endoclip could have an influence on abdominal dissemination, implantation and local luminal recurrence. Therefore, endoscopists should have a strong ability for depth diagnosis. With respect to this, some previous reports have shown that high diagnostic performance is a predictive factor for successful colorectal ESD [12, 18-23]. Hence, trainees should increase their diagnostic ability using magnifying endoscopy prior to starting colorectal ESD. If the trainees estimate lesions as a submucosal invasive cancer, endoscopic resection for diagnostic purposes should be avoided.

An important issue in the standardization of colorectal ESD is perforation, which is related to the thickness of the colonic wall. In this study, we observed a perforation rate of $4 \%$. Saito et al. [2] reported the results of a large-scale, prospective, multicenter study of colorectal ESD. In this previous study, the clinical outcomes were analyzed according to the total number of colorectal ESDs. The perforation rate was about $5 \%$ in the experienced group. Hence, the perforation rate in the present study should be considered to be within an allowable range. Moreover, this relatively low rate likely resulted from the presence of experienced endoscopists. In other words, trainees in the initial stages of colorectal ESD should perform under the guidance of experienced endoscopists with a great deal of familiarity with the procedure to ensure its safety. Addi-
40

Digestion 2014;89:37-42 DOI: $10.1159 / 000356215$
Sakamoto et al. 
tionally, patients who are judged to have a perforation can be treated with the administration of antibiotics and abstinence from food. Hotta et al. [24] reported that nonsurgical treatment after perforation caused by colorectal ESD was allowable in the presence of complete closure of the mucosal defect or absence of diffuse peritonitis. It is also important to note that most of the perforations that occurred during the ESD procedure in the present study were minor perforations, and trainees should have knowledge of troubleshooting for perforations.

This study had several limitations. First, the clinical data was obtained from only a single center. At present, various devices have been developed for use in ESD and can be selected based on preference. In our institution, we primarily used the B-B knife because of the lower risk of perforation. However, this knife is not in widespread use even in Japan, and its use could have influenced the study results. Second, it was not possible to evaluate the assistance by the supervisors. In our previous study, the completion rate was one of the important outcomes, and trainees required experience with $>30$ cases to perform colorectal ESD without guidance from an experienced specialist. In the present study, some of the procedures might have been difficult for the trainees to complete alone; therefore, the clinical results may have been influenced from a technical perspective. Given these limitations, a future prospective multicenter study correcting for the completion rate should be performed to better evaluate the practical clinical outcomes.

In conclusion, lesion size had a significant effect on the length of the procedure for trainees performing colorectal ESD. We found that an LST-G-type lesion of $<40 \mathrm{~mm}$ is likely to be suitable for introducing trainees to ESD. Moreover, resection of a submucosal invasive cancer was technically difficult in a short procedure time. Hence, trainees should be required to have a strong ability to perform depth diagnosis prior to attempting ESD.

\section{Disclosure Statement}

The authors have no disclosures relevant to this publication.

\section{References}

-1 Saito Y, Uraoka T, Matsuda T, Emura F, Ikehara H, Mashimo Y, Kikuchi T, Fu KI, Sano Y, Saito D: Endoscopic treatment of large superficial colorectal tumors: a case series of 200 endoscopic submucosal dissections (with video). Gastrointest Endosc 2007;66:966-973.

-2 Saito Y, Uraoka T, Yamaguchi Y, Hotta K, Sakamoto N, Ikematsu H, Fukuzawa M, Kobayashi N, Nasu J, Michida T, Yoshida S, Ikehara H, Otake Y, Nakajima T, Matsuda T, Saito D: A prospective, multicenter study of 1,111 colorectal endoscopic submucosal dissections (with video). Gastrointest Endosc 2010;72:1217-1225.

-3 Oka S, Tanaka S, Kanao H, Ishikawa H, Watanabe T, Igarashi M, Saito Y, Ikematsu H, Kobayashi K, Inoue Y, Yahagi N, Tsuda S, Simizu S, Iishi H, Yamano H, Kudo SE, Tsuruta O, Tamura S, Saito Y, Cho E, Fujii T, Sano Y, Nakamura H, Sugihara K, Muto T: Current status in the occurrence of postoperative bleeding, perforation and residual/local re currence during colonoscopic treatment in Japan. Dig Endosc 2010;22:376-380.

4 Niimi K, Fujishiro M, Kodashima S, Goto O, Ono S, Hirano K, Minatsuki C, Yamamichi N, Koike K: Long-term outcomes of endoscopic submucosal dissection for colorectal epithelial neoplasms. Endoscopy 2010;42:723-729.
-5 Toyonaga T, Man-i M, Fujita T, East JE, Nishino E, Ono W, Morita Y, Sanuki T, Yoshida M, Kutsumi $\mathrm{H}$, Inokuchi $\mathrm{H}$, Azuma $\mathrm{T}$ : Retrospective study of technical aspects and complications of endoscopic submucosal dissection for laterally spreading tumors of the colorectum. Endoscopy 2010;42:714-722.

6 Saito Y, Kawano H, Takeuchi Y, Ohata K, Oka S, Hotta K, Okamoto K, Homma K, Uraoka T, Hisabe T, Chang DK, Zhou PH: Current status of colorectal endoscopic submucosal dissection in Japan and other Asian countries: progressing towards technical standardization. Dig Endosc 2012;24(suppl 1):67-72.

7 Repici A, Hassan C, De Paula Pessoa D, Pagano N, Arezzo A, Zullo A, Lorenzetti R, Marmo R: Efficacy and safety of endoscopic submucosal dissection for colorectal neoplasia: a systematic review. Endoscopy 2012;44:137150.

$>8$ Lee EJ, Lee JB, Lee SH, Kim DS, Lee DH, Lee DS, Youk EG: Endoscopic submucosal dissection for colorectal tumors - 1,000 colorectal ESD cases: one specialized institute's experiences. Surg Endosc 2013;27:31-39.

-9 Nakajima T, Saito Y, Tanaka S, Iishi H, Kudo SE, Ikematsu H, Igarashi M, Saitoh Y, Inoue Y, Kobayashi K, Hisasbe T, Matsuda T, Ishikawa H, Sugihara KI: Current status of endoscopic resection strategy for large, early colorectal neoplasia in Japan. Surg Endosc 2013;27:3262-3270.
10 Sakamoto T, Saito Y, Fukunaga S, Nakajima T, Matsuda T: Learning curve associated with colorectal endoscopic submucosal dissection for endoscopists experienced in gastric endoscopic submucosal dissection. Dis Colon Rectum 2011;54:1307-1312.

11 Watanabe T, Itabashi M, Shimada Y, Tanaka S, Ito Y, Ajioka Y, Hamaguchi T, Hyodo I, Igarashi $M$, Ishida $H$, Ishiguro $M$, Kanemitsu $Y$, Kokudo N, Muro K, Ochiai A, Oguchi M, Ohkura Y, Saito Y, Sakai Y, Ueno H, Yoshino T, Fujimori T, Koinuma N, Morita T, Nishimura G, Sakata Y, Takahashi K, Takiuchi H, Tsuruta O, Yamaguchi T, Yoshida M, Yamaguchi N, Kotake K, Sugihara K: Japanese Society for Cancer of the Colon and Rectum (JSCCR) guidelines 2010 for the treatment of colorectal cancer. Int J Clin Oncol 2012;17:1-29.

12 Matsuda T, Fujii T, Saito Y, Nakajima T, Uraoka T, Kobayashi N, Ikehara H, Ikematsu H, Fu KI, Emura F, Ono A, Sano Y, Shimoda T, Fujimori T: Efficacy of the invasive/non-invasive pattern by magnifying chromoendoscopy to estimate the depth of invasion of early colorectal neoplasms. Am J Gastroenterol 2008;103:2700-2706.

13 Nonaka S, Saito Y, Fukunaga S, Sakamoto T, Nakajima T, Matsuda T: Impact of endoscopic submucosal dissection knife on risk of perforation with an animal model-monopolar needle knife and with a bipolar needle knife. Dig Endosc 2012;24:381. 
14 Schlemper RJ, Riddell RH, Kato Y, Borchard F, Cooper HS, Dawsey SM, Dixon MF, Fenoglio-Preiser CM, Fléjou JF, Geboes K, Hattori T, Hirota T, Itabashi M, Iwafuchi M, Iwashita A, Kim YI, Kirchner T, Klimpfinger M, Koike M, Lauwers GY, Lewin KJ, Oberhuber G, Offner F, Price AB, Rubio CA, Shimizu M, Shimoda T, Sipponen P, Solcia E, Stolte M, Watanabe $\mathrm{H}$, Yamabe $\mathrm{H}$ : The Vienna classification of gastrointestinal epithelial neoplasia. Gut 2000;47:251-255.

15 Matsumoto A, Tanaka S, Oba S, Kanao H, Oka S, Yoshihara M, Chayama K: Outcome of endoscopic submucosal dissection for colorectal tumors accompanied by fibrosis. Scand J Gastroenterol 2010;45:1329-1337.

16 Kim ES, Cho KB, Park KS, Lee KI, Jang BK, Chung WJ, Hwang JS: Factors predictive of perforation during endoscopic submucosal dissection for the treatment of colorectal tumors. Endoscopy 2011;43:573-578.
17 Hayashi N, Tanaka S, Kanao H, Oka S, Yoshida S, Chayama K: Relationship between narrow-band imaging magnifying observation and pit pattern diagnosis in colorectal tumors. Digestion 2013;87:53-58.

18 Sakamoto T, Saito Y, Nakajima T, Matsuda T: Comparison of magnifying chromoendoscopy and narrow-band imaging in estimation of early colorectal cancer invasion depth: a pilot study. Dig Endosc 2011;23:118-123.

19 Fukuzawa M, Saito Y, Matsuda T, Uraoka T, Itoi $\mathrm{T}$, Moriyasu F: Effectiveness of narrowband imaging magnification for invasion depth in early colorectal cancer. World J Gastroenterol 2010;16:1727-1734.

20 Kobayashi Y, Kudo SE, Miyachi H, Hosoya T, Ikehara N, Ohtsuka K, Kashida H, Hamatani S, Hinotsu S, Kawakami K: Clinical usefulness of pit patterns for detecting colonic lesions requiring surgical treatment. Int J Colorectal Dis 2011;26:1531-1540.
21 Matsumoto K, Nagahara A, Terai T, Ueyama H, Ritsuno H, Mori H, Nakae K, Beppu K, Shibuya T, Sakamoto N, Osada T, Ogihara T, Yao T, Watanabe S: Evaluation of new subclassification of type $\mathrm{V}(\mathrm{I})$ pit pattern for determining the depth and type of invasion of colorectal neoplasm. J Gastroenterol 2011;46: 31-38.

22 Ikehara H, Saito Y, Matsuda T, Uraoka T, Murakami Y: Diagnosis of depth of invasion for early colorectal cancer using magnifying colonoscopy. J Gastroenterol Hepatol 2010;25: 905-912.

23 Ikematsu H, Matsuda T, Emura F, Saito Y, Uraoka T, Fu KI, Kaneko K, Ochiai A, Fujimori T, Sano Y: Efficacy of capillary pattern type IIIA/IIIB by magnifying narrow band imaging for estimating depth of invasion of early colorectal neoplasms. BMC Gastroenterol 2010;10:33.

24 Hotta K, Shinohara T, Oyama T, Ishii E, Tomori A, Takahashi A, Miyata Y: Criteria for non-surgical treatment of perforation during colorectal endoscopic submucosal dissection. Digestion 2012;85:116-120. 